Article

\title{
The New Visual Testimonial: Narrative, Authenticity, and Subjectivity in Emerging Commercial Photographic Practice
}

\author{
Heather Morton \\ Photography Department, Sheridan College, Oakville, L6H 2L1, Canada: E-Mail: heather.morton@sheridancollege.ca
}

Submitted: 31 October 2016 | Accepted: 9 December 2016 | Published: 29 March 2017

\begin{abstract}
By studying the cultural and aesthetic impact of increasingly pervasive digital technologies and mass amateurization, this paper examines the ramifications of the networked information economy on professional photographic practice and considers the concomitant implications for the photographic classroom. Using the framework of convergence culture as per the writings of Yochai Benkler, Henry Jenkins, Mark Deuze, and Axel Bruns, the impact of accessible and instantaneous image creation and dispersal are explored. Given the rise of consumer engagement in brand co-creation on social media platforms, we can observe massive changes to professional practice in areas such as aesthetics, and the erosion of previous sustainable business models. Indeed, as traditional notions of "expertise" shift from technological prowess to narrative and disseminative abilities, the effects on commercial practice and photographic education need to be addressed. This paper argues that there are three emerging priorities for commercial image use: narrative ability, authenticity, and subjectivity and suggests initial steps in their pedagogical application. By acknowledging these transformations, this paper explores the idea that students need to harness technique, social media influence, adaptability, subjectivity, and storytelling power in order to better serve emerging image-based needs in commercial spaces.
\end{abstract}

\section{Keywords}

brand co-creation; commercial photography; convergent culture; Instagram; marketing; post-secondary education; social media; user generated content

\section{Issue}

This article is part of a multidisciplinary issue of Media and Communication, edited by Mark Cocks (University of Wales Trinity Saint David, UK) and Michelle Bogre (The New School, USA).

(C) 2017 by the author; licensee Cogitatio (Lisbon, Portugal). This article is licensed under a Creative Commons Attribution 4.0 International License (CC BY).

\section{Introduction}

In the summer of 2010, Domino's Pizza launched an advertising campaign called Show Us Your Pizza in which they pledged to forego the traditional tools and tricks of commercial food photography and would instead "shoot their pizzas just the way they come out of the oven" (Lincoln, 2013). This was part of a larger "Turnaround" campaign in which Domino's acknowledged (and indeed showcased) consumer dissatisfaction with their product and subsequently revamped the recipe. In order to engage the consumer in this rebranding strategy, Domino's encouraged customers to photograph their own pizza exactly as it arrived at their door and upload the photos to a dedicated URL. These images populated a cu- rated, but not manipulated, website of user generated pizza pictures.

This aspect of the Show Us Your Pizza campaign was part of a bigger strategy that integrated online and massmarket motion spots, online games, and a social media strategy. The goal was to get the consumer engaged with the improved Domino's pizza in what could be perceived as an experiential and authentic way. The campaign resulted in a $14 \%$ increased market share, a slew of press coverage, and various coveted marketing awards (Lincoln, 2013; Litz, 2010). For Domino's, Show Us Your Pizza heralded the beginning of what would be a continued commitment to consumer engagement through a number of marketing channels and has resulted in consistent growth for the brand; increasing their market share most 
recently from 9 to $12.3 \%$ between 2014 and 2016 (Derousseau, 2016; He, Zha, \& Li, 2013).

Although by no means unique in this respect, the Show Us Your Pizza campaign represents the culmination of the possibilities for consumer engagement and the threat to established protocols and priorities in the networked information economy. Acting as an unwitting harbinger, a Domino's chef insists: "We know that [the consumer is] the authentic source for great Domino's pizza pictures [emphasis added]" (Litz, 2010).

This essay considers the effects on the commercial photography industry endemic to the massive changes in the way culture is now created and consumed. As this paper will show, the framework of convergence culture has lead to a climate in which previous barriers to entry have been negated, lines delineating professional and amateur engagement with photography have been blurred, and new opportunities for consumer involvement have been introduced. As such, new priorities have emerged which privilege authenticity, subjectivity, and narrative ability. This essay will explore these three key attributes that are increasingly integral to image use in commercial contexts, and will consider appropriate opportunities for their integration in post secondary commercially focused photography programs.

To fully appreciate the cultural changes of the last two decades, it is necessary to understand the framework in which the public is consuming (and producing) media in the networked information economy. Though the theorists I reference are preoccupied with a variety of content creation (from citizen journalism to Wikipedia to Flickr and gaming), their prosumption critiques can also be applied singularly to the sphere of commercial media.

\section{Consumer Engagement and Convergence Culture}

The related concepts of produsage, the prosumer, and convergence culture have attracted attention from a range of theorists working from a political economy and critical perspective. Not surprisingly, this scholarship has also garnered interest from marketing industry strategists, who are eager to adopt new models of consumer engagement. This shifting interest, which has resulted in the widespread inclusion of non-professionals in content creation, has serious ramifications on heretofore predictable and sustainable photography-based careers. It is important therefore to understand the consumptive and productive atmosphere as identified in the writings of Bruns, Benkler, Jenkins, and Deuze after starting with Alvin Toffler to provide a bit of early and prescient context to our current state of commercial image use.

The prosumer was first named by Toffler and described in his book The Third Wave published in 1980. Toffler suggests that in the next stage of human innovation, culture would be typified by, among other things, a demassification of the media (p. 165) and the rise of the prosumer. The name prosumer describes the phe- nomenon in which we are increasingly active in the production of things that we then consume (p. 265). In a produsage paradigm, not only should marketing be tailored to the consumer's interests but she should also have agency in creating the things with which she is surrounded (if not creating the actual marketing itself as per user generated content in general and the Domino's example in particular). Due to the advent of digital technology and the concomitant rise of instant, targeted communication, these desires can be accomplished to an increasingly satisfactory degree. Axel Bruns' 2008 book Blogs, Wikipedia, Second Life, and Beyond: From Production to Produsage, elaborates on Toffler's thesis by outlining the major characteristics of produsage as "the collaborative, iterative, and user-led production of content by participants in a hybrid user-producer, or produser role" (p. 1). In a review of the book, David Karpf (2009) outlines the four main tenets of produsage as: "(a) open participation, communal evaluation, (b) fluid heterarchy, ad hoc meritocracy, (c) unfinished artefacts, continuing process, and (d) common property, individual rewards" (p. 81). That the characteristics of produsage themselves are anathema to a "professional" practice should be obvious but it will be discussed further below.

Yochai Benkler is optimistic about the potential for change inherent in this new approach to content creation. In his book The Wealth of Networks (2006), he situates our current media landscape in its historical context and suggests that we might consider mass culture as having been democratized because its creative potential is now in the hands of the individual. He writes: "The networked information economy also allows for the emergence of a more critical and self-reflective culture" (p. 15) and this has "made human creativity and the economics of information itself the core structuring facts in the new networked information economy" (p. 4).

In an editorial written by Henry Jenkins and Mark Deuze (2008) on the idea of convergence culture, they consider Benkler's theory of hybrid media ecology which acts in a transformative way on all content producers including those working in commercial, political, activism, and journalism contexts (p. 5). Taking it a step further, Jenkins and Deuze (2008) claim that individuated content is less important than the actual collaborative experience of building the content in shared spaces. They suggest the pre-eminence of this "socialized media" of which the photo sharing site Flickr is named as an example (p. 5). So again, we see that collaboration and creativity is crucial to our engagement with culture.

In his earlier essay The Cultural Logic of Media Convergence, Henry Jenkins (2004) catalogues the myriad of ways the consumer is engaged with established and remixed media across multiple channels. He hints at the overall effect of these shifting relationships, explaining convergence culture as "a reconfiguration of media power and a reshaping of media aesthetics and economics" (p. 35). Note the care he takes to name aesthetics as an area worthy of consideration. To put it another 
way, Jenkins and Deuze (2008) explain, "the flow of media content is shaped as much by the decisions made in teenagers' bedrooms as it is by decisions made in corporate boardrooms" (p. 7).

Clearly there are some common themes across these theoretical frameworks which are useful in identifying the key attributes of convergence culture: a desire to be creative, a desire for customized content, a desire to collaborate with others, and a desire for shared spaces in which collaboration might take place. Turning back for a moment to the Domino's example used at the beginning of this essay, we can see that Show Us Your Pizza successfully harnesses and fulfills these desires while simultaneously eroding the prospects for professional photographers.

Certainly an analysis of contemporary marketing priorities illustrates the increasing value of collaborative spaces and user generated content (UGC). Not surprisingly, the corollary is also true; traditional marketing approaches are experiencing a retraction in their use and value, and a concomitant reallocation of their media budgets (Banet-Weiser, 2011; Gotter, 2016; Lyngsfeldt, 2015; Moore, 2015). In an aggregate analysis of 2014 and 2015 marketing data, London agency Freely cites a study which suggests that by 2019, mobile advertising will represent $72 \%$ of all US digital ad spending (Moore, 2015). Quoting the Social Media Examiner, the analysis includes this finding: "Figuring out how to best connect with people remains high on the list of questions marketers want answered (89\%). As more businesses become social, those that best engage will stand out" (Moore, 2015).

UGC consistently outperforms traditional media in areas of "trust" and "helpfulness" (Gotter, 2016) so much so that in a directed analysis on attitudes towards visualbased UGC, Olapic found that consumers trusted user generated visual content almost twice as much as professional images created by brands (Olapic, 2016) and more than half of those surveyed said that they "were more likely to click on an ad employing UGC than one using stock photography" (Leggatt, 2016).

Hence, as a result of the technical, aesthetic, and disseminative abilities of the networked information economy expressed in the bundling of the camera phone, social media, and the internet, we find a systematic erosion of traditional sustainable photographic practice. The accompanying democratizing shifts in aesthetic ambitions and access, coupled with an engagement hungry public vis a vis convergence culture, may have led to a schism between what we teach and the image-making skills required in commercial spaces. This essay will illuminate what brands want from their imagery, and consider how we can deliver industry ready practitioners given these findings.

\section{3. "Professional" as a Questionable Distinction}

To begin it is important to understand the erosion of traditional and long-standing notions of what consti- tutes professional practice. According to the membership guidelines found on the website of the American Society of Media Photographers (ASMP), professional membership is reserved for photographers working in either still or motion who have been "actively and consistently engaged in professional practice for at least 3 years" (ASMP, 2016). This definition is considerably more vague than the stipulations found on the website in 2013 which used concrete achievements to signal professionalism, prioritized publication, and required its members to be earning at least $50 \%$ of their primary income from licensing their photography (ASMP, 2013). This shift away from a quantitative approach is telling. The Professional Photographers of Canada (PPoC) uses similarly vague language, welcoming "photographers of all genres", and suggesting that membership will help attain accreditation as a "professional", without ever specifying what that entails (PPoC, 2016). In the case of the Canadian Association of Professional Image Creators (CAPIC), the eligibility for membership requires meeting several criteria, and puts emphasis on having an appropriate portfolio and business documentation in addition to proof of publication (CAPIC, 2016).

Despite the ambiguities, there remains a loose collection of characteristics which seem to constitute professionalism from an industry standard perspective: a sustained record of successful jobs (having been published), the use of professional business documents (which may indicate whether the prospective member considers maintaining a sustainable fee structure important), that there is an existing body of work which corresponds to some agreed upon presentation standards (the portfolio), and that the majority of income is made from photography.

These defining features stand in contrast to the trends of mass amateurization which problematize the traditional distinction between professional photographer and everyone else with a camera. Further to the collaborative, creative and consumptive desires of convergence culture, non-professional image makers are eager to participate in the creation of mass marketing campaigns like Show Us Your Pizza, so much so that one 2016 consumer trend study claims that over 50\% of respondents actually want more opportunities and direction from brands on what content to create (Gotter, 2016). Likewise, the platforms that are so heavily foundational to convergence culture (Instagram, Flickr, Facebook, Twitter, Snapchat) facilitate the process by which advertisers can utilize the branded work being done by the public to their own promotional and disseminative ends. This newly "commercial" work includes everything from UGC, to sponsored hashtags, to working with "influencers" (Kolm, 2015). This illuminates the false distinction between professional and non (Duffy, 2010; San Cornelio \& Gomez Cruz, 2014; Schroeder, 2013) and nullifies the need for proof of professional practice. Referencing Prahalad and Ramaswamy, Banks and Deuze (2009) state that in fact "value is increasingly co-created by both the firm and the consumer. Today, media consumers, fans 
and audiences are redefined as 'the drivers of wealth production within the new digital economy'"' (p. 420), resulting in diminished opportunities for professional creative practitioners overall.

In the end, non-professionals want to create work for brands, they have the ability to do so and to spread this work around, and brands are happy to receive and use this work on their own disseminative media platforms. In addition, the technical and aesthetic barriers to entry have been dismantled: camera technology has gained precision and image capture has advanced to include ever-larger digital sensors, having the gradual effect that images taken with smaller cameras can more accurately retain their integrity when reproduced at bigger sizes (the recent Shot on an iPhone campaign is a relevant example). Plus, aesthetic banality delivers its own branding benefits as will be shown below.

Thus there is an emerging strata of non-professional image-makers who are engaging with brands for a variety of reasons that sit outside of the typical sustainability goals of professional practice. Instead, they report that their participation delivers the following: an increase in social capital, pleasure in being part of brand co-creation, a creative challenge, an outlet for self-expression, and a sense of empowerment. (Brabham, 2008; Duffy, 2010; Marcus Reker, 2016; Nava, Blake, MacRury, \& Richards, 2013; San Cornelio \& Gomez Cruz, 2014). Certainly in these emerging marketing contexts, there is no inherent need for a "professional" approach as defined by the ASMP, PPoC and CAPIC above: business documents and portfolios don't apply and proof of prior paid remuneration is beside the point. Furthermore, as we will see below, the authenticity aspect of these ads also leaves any aesthetic or technical professionalism out of the picture by necessity.

Certainly, our presumptions about photographic "work" need to change. Speaking recently at the Image Truth/Story Truth symposium, conference panelists Stephen Mayes and Fred Ritchin reject the handwringing fixation on recompense, suggesting that in fact there are numerous emerging revenue streams for photographers, many of them non-traditional and some necessitating collaboration with non-professionals (Tow Centre, 2015). Ritchin goes further to call for a change in the way professionalism is defined, arguing for example, that the citizen journalist may be better equipped (mostly from an access perspective) to provide the most appropriate images from a conflict (Tow Centre, 2015). Similarly, referencing the quote used above from Jenkins and Deuze (2008), one could certainly argue that the proverbial teenager in the bedroom is indeed a more appropriate mediator of visual identity for many brands eager to engage with exactly that demographic.

Without a doubt, given the erosion of traditionally stable revenue streams, commercial photographic education at the post secondary level has a responsibility to ensure that our students become fully cognizant of the field in which they are entering-one that is crowded with powerfully engaged, connected, and able consumers and one that is susceptible to influence from the aesthetic approach that these consumers bring.

\section{New Priorities: Storytelling, Subjectivity, and Authenticity}

This essay identifies three key emerging priorities that are critical components of contemporary commercial image culture as:

A. Storytelling or narrative abilities;

B. The importance of authenticity;

C. Expressions of subjectivity.

As this essay will show, these priorities can give direction to emerging image creators and should prompt educators in commercially focused programs to ensure that our pedagogical approach enables our students to understand, and execute along these shifting priorities.

\section{The Persistence of Storytelling}

Though convergence culture encourages the micro and diverse participation of consumers in brand co-creation, the sophistication of a marketing strategy considered as a whole also requires rich storytelling which can engage the audience at an emotional and experiential level (Olapic, 2016; Scoblete, 2015). When brands pursue UGC, this can take the form of co-created narratives (Deuze, 2005) enabled by accessible and transformative technology (Harper, 2016). However, there is also an increasing need for intentional affect, which triggers emotional responses using implicit associations.

In her case analysis of the Instagram presence of Nike and Starbucks, Chia Yu Chang (2014) contrasts hard and soft sell tactics, finding that in the case of the latter: "These appeals tend to be subtle and indirect; an image or atmosphere may be conveyed through a beautiful scene or the development of an emotional story" (pp. 21-22). In Chang's analysis, she characterizes UGC as most often simple and direct, and explicit in its support for the brand. On the other hand, the intentional posts generated by Nike and Starbucks worked at the implicit level, leveraging visual messages designed to "delight and inspire" (p. 37). Arguably this ability to tell a complex story and seed an emotional experience in a single image is a challenge which requires skill beyond the ease of the snap/filter/hashtag/post/repeat cycle. Iterative and reflective practice is appropriate and necessary to this goal.

Though Eric T. Meyer's (2015) study considers the pedagogical ramifications in a motion context, his assessment of the use of iPad's in a filmmaking classroom is related and applicable for our purposes. He finds that "the expertise being taught is no longer necessarily in the technical areas of manipulating filming equipment and editing suites, but in the area of storytelling and teaching 
students collaborative and creative working techniques" (p. 311). Note the shift away from technical concerns in favour of collaborative and narrative development as an area of differentiation vis a vis non professional image makers. Though this is in some ways a false dichotomy, the perceived valuation shift is noteworthy. Certainly in low-resolution, social media spaces, technical skill isn't privileged nor is it even differentiated (San Cornelio \& Gomez Cruz, 2104). In fact, in Lawrence, Fournier, and Brunel's (2013) study of the effectiveness of consumer generated advertising, they found that "authenticity and creativity judgments figure prominently in people's attitudes towards consumer generated advertising and that executional quality may be traded off for these benefits" (p. 297). This isn't to suggest that technical prowess and "quality" are not important parts of commercial photographic education but rather that they shouldn't be of singular focus.

Given the above, I would argue that this prioritizing of narrative abilities must be addressed explicitly and persistently in the curriculum throughout the post-secondary education experience. Emphasis must be placed on understanding the relationship between semiotics, composition, and rhetorical emotional cues. As per Chang's point, this is a subtle and ephemeral expectation, but rich in conceptual opportunity. Undoubtedly this is already part of most commercial photographic curricula but I would argue that we need to integrate narrative goals into even the most technical and/or foundational assignments. An appropriate question to ask our students might be "How is the brand illuminated figuratively as well as literally through each particular lighting choice?

This also requires an understanding of the brand story in and of itself in order to provide an application of technique that fits the brand (rather then a dependence on default rules of product lighting for example). Studying the stories that brands tell about themselves and understanding the subtleties between differentiating identities of competitors in crowded sectors is crucial in order to anticipate the look and feel that might be most appropriate. There is value then in an historic understanding of the complexities of visual messaging changes and their progression through time. Lessons in the history of the use of photography in commercial contexts helps enmesh this understanding as a crucial part of brand partnerships on the part of working photographers. As an author of such a course, I find it is useful to track the changes in our collective approach to the use of applied visuals throughout the last century and to acknowledge that advertising "works on us" in different ways over time. As a result of this study, students begin to appreciate the impact of larger socio-economic trends on commercial expression and can start to anticipate the ways in which aspects of current culture and values are being articulated in the type of imagery we use and how we use it. Through specific case studies, they begin to understand how brands variously deal with growing product parity, product diversification, and in- creasing media differentiation and dispersion. Students are thusly enabled to apply a critical framework to speculative, future work, and emerging areas of image use.

There is value too in participating in social media spaces and experimenting with the inherent and differentiated narrative attributes which these spaces provide (certainly as opposed to only lamenting the loss of traditional media). Plus, social media platforms are being constantly innovated by artists wanting to use these new mediums to tell stories in unique ways. Two foundational examples are Rachel Hulin's Instagram novel Hey Henry Hey Matilda (Dewey, 2015) and Amalia Ulman's 2104 Instagram Art Project (Sooke, 2016). An awareness of innovation and experimentation in various realms of image use is crucial and informative, and will well situate our students for future innovations.

Indeed, this might also be a matter of clearly deconstructing a perceived and sometimes entrenched separation between "types" of photography within the structure and rhetoric of our programs. I would argue that keeping documentary, fine art, and advertising photography siloed (never mind the problematic division between moving and still images), is not appropriate given the increasing porousness of these areas and our need to pull from the persuasive approaches of each. This is echoed in the marketplace; newly formed agencies like NAMARA Reps and Getty's Verbatim agency (Laurent, 2016) are catering to the interest corporations have in telling authentic stories using narrative techniques inherent to the professional practice of photojournalists. Speaking about a recent project, Jane Mackie, Vice President of the Fairmont Hotel Brand mused: "Working with NAMARA has given us an opportunity to capture some of [our employee's] incredible stories and showcase them in a way that is authentic and meaningful" (Marketwired, 2016). Developments like these represent new opportunities for innovative image-makers who are willing to look beyond traditional professional barriers and reject the biases contained therein.

\section{Authenticity and Aesthetic Creep}

The desire for authenticity as voiced in the quote above from Fairmont Hotels is reminiscent of the Domino's chef's insistence that the consumer is really the best source of authentic photographs. Considered together, the underlying assumption is clear: the polish of a traditional commercial image is misleading and untrustworthy. This distrust has important but not unprecedented aesthetic consequences.

A vernacular photographic style began to appear in advertising in the 1990's due in part to the influence of the visual tropes of post-modernism (Schroeder, 2013). This had the effect of privileging real, authentic, snapshot-type images in mass-market contexts as more truthful to a marketing-weary and skeptical public (Berger, 2011; Schroeder, 2008). At the time, these "snapshots" were produced by professional commercial photogra- 
phers like Terry Richardson, who reported preferring small, compact, point-and-shoot cameras for their ability to capture spontaneity and realness (Schroeder, 2008, pp. 284-285). In these cases, photographers were adopting and recreating the aesthetic qualities of the vernacular (to varying degrees: skewed composition, directional and harsh lighting, unflattering poses, image grain, over or underexposure, etc.) while still engaging multiple production elements and intentionally applied technical skill.

Meanwhile, in the early 2000's the rise of participation in online image sharing spaces begins to reinforce a similar vernacular aesthetic. These platforms privileged the mundane and the everyday experiences of life (Chang, 2014; Frey, 2012; Hjorth, 2008; Wagner, 2011). As a result, the banal visual tropes that were endemic to this type of diaristic image-making became associated with inherently authentic and real, in-between moments (Hjorth, 2008; Schroeder, 2013). As the desires of convergence culture became doubly encouraged and fulfilled by this online visual engagement and expression, marketers began to participate. By harnessing content created in these spaces, brands are able to borrow authenticity from the presumed aesthetic neutrality of these types of images. Indeed, authenticity is seen increasingly as a competitive advantage (Frey, 2012; Scoblete, 2015) and gives the brand more credibility in the marketplace (Deuze, 2005; Duffy, 2010; Lyngsfeldt, 2015; Uzunoğlu, 2011). As such, user generated ads are proving to be more successful than brand initiated campaigns by several metrics (Gotter, 2016; Lawrence et al., 2013; Lyngsfeldt, 2015; Olapic, 2016). As Schroeder (2013) explains: "This imagery serves to distance the brand from corporate control, associating it instead with consumer cocreation". Uzunoğlu (2011) elaborates: "as [it] is peercreated, it may have higher credibility and trustworthiness than company provided messages" (p. 148). And in Schroeder's (2013) research, he found "Thus, from the point of view of the brand manager, snapshot aesthetics offers a way into a participatory (consumer generated images), sincere and less directive (more ambiguous and flexible, perhaps) strategic style".

However, the rise of Instagram and the wide use of filters on that platform belie the snapshot aspect of these images. Indeed, the filters act to mediate these "banal" moments and as such, it is important to acknowledge the creeping aesthetic engagement of consumers in online image sharing spaces. Frey (2012) emphasizes the communicative usefulness of these capabilities and hints at the challenge for aspiring "professional" photographers: "These image processing features further enable the extension of photographic practice by reducing the threshold of competence required to produce appealing images with what were hitherto expensive professional, and difficult to master effects" (p. 27). In many cases then, there is a consistent effort to improve technique, develop a personal style and to engage in a practice that is more deliberate (Zappavigna, 2016, p. 3).
With this in mind, it is important to note that broad amateur photo expression has a duality: it is both banal and tries to look professional. Likewise for aspiring image-makers, desired visual expressions on social media are authentic but mediated, and participate in a mutually reinforcing loop of influence. More research is warranted in parsing the figurative layers and trade-offs contained in these images; analyzing, among other things, aesthetic engagement, access to brands and products, and the influence of dispersive communities.

Regardless, established photographers are competing with actual brand users whose visual testimonials are mostly unquestioned as authentically (more) pure, freely given, and shot without artifice. Plus, they are happening in real time in a way that can be organized and reconstituted through hashtags, likes, and reposts by the brand or others. From a photographic education perspective then, a brand approach that is "less directive" has some serious ramifications. Indeed, if brandheavy mass-market communication is waning in favour of interactive social media and experiential based campaigns (Moore, 2015) there might be less opportunity for stylized, technique-rich imagery. Arguably, technical "mastery" as a singular or primary focus has been devalued. Having said this, there will always be a need for well-crafted lighting, considered tone and mood, and innovative aesthetic approaches on some marketing platforms (and certainly in terms of narrative ability as discussed above) but the prevailing trend towards "authenticity" has unquestionably empowered non professional image-makers who are already active in many brand enabled spaces. Is it necessary then to shift our learning outcomes to consider the possibility that technical skill is not the ultimate differentiator anymore?

Indeed, it is instructive to consider which aesthetic qualities can signal authenticity and understand how and when they might be engaged. Though technical skill and mastery is important in theory, students need to be taught to parse the particular client needs as they might align with context: where will this image appear, how long will it last, what is the experience it is designed to provoke? And after mastery is achieved, students need to be able to understand the importance of occasionally and thoughtfully "breaking the rules" of commercial lighting and composition and that "bad" photography delivers its own set of connotations which may be useful in certain marketing scenarios (as an example: Viviane Sassen's 2013 campaign for Carven in which the focus lies in the deep background landscape, leaving the foregrounded dress and model, presumably the point of the ad, very soft, the details of the dress having been completely obscured. KesselsKramer's long running work for the Hans Brinker Budget Hotel is another notable example). Also, it is important to review the visual tropes of the vernacular and their value from an historic perspective in order to appreciate the legacy of our ambiguous relationship with reality and fantasy in commercial imagery. How does a brand's shifting interest or en- 
gagement in "reality" challenge our assumptions about proper commercial work?

Furthermore, can instructed image-makers also participate in authentic brand experiences and reflect that back in non-traditional advertising spaces? This again suggests that there is value in understanding what the central brand qualities are in order to then capture and reflect those attributes. I would argue that our students need to go beyond the cliché "shoot in the style of your favourite brand" assignment and parse the platforms that pair with a particular visual approach for a specific client. They should be able to defend their aesthetic choices based on their understanding of the medium as well as the brand guidelines. In fact, there may well be untapped opportunity here. There is reason to believe that marketers are struggling to keep up with the demands of content hungry, multi-channel platforms. Considering advertorials in particular, a Photo District News article asserts "The hard part for agencies may be getting their heads around the type of content that best reflects their clients" (Ahearn, 2013). It will be to their advantage if our students can add value by applying an understanding of the medium coupled with an ability to execute across various narrative needs.

Similarly, the image-maker's own brand needs to be perceived as authentic as well. As we will see below, expressions of subjectivity can help deliver this message of authenticity; social media provides an ideal promotional space for this exploration and it can be harnessed to showcase all manner of image-based work, personal relationships, preferences, and experiences. As per a report from a 2015 PhotoPlus panel on this topic: "the route to success in social media doesn't follow a neat script and has far less to do with a given tactic and far more to do with honesty, positivity and having something of value to share with the world" (Scoblete, 2015).

\section{Subjectivity and the Visual Testimonial}

Imbedded in the attributes and desires of convergent culture is a preoccupation with subjectivity; processes of self-creation, re-inventing and performance have been encouraged and indulged by mobile media and the cameraphone (Gómez Cruz \& Meyer, 2012). At the same time, social media platforms which allow individuated and targeted messaging, are becoming more central to brand communications as outlined above. As a result, brands are able to engage in value co-creation with their consumers, in part by highlighting their customer's subjective experiences with their products (Chang, 2014; Schroeder, 2013). This can in turn influence the brand's own visual approach (Gillett, 2014), exacerbating the divide between mass marketing, top-down approaches and organic, subjective and spontaneous expressions of brand engagement. In addition, consumers are also exploring their own identities in online spaces with reference to the established narratives of products, brands and corporate messages (Frey, 2012).
In her consideration of the use of Instagram, Zappavigna (2016) characterizes the personal expressions of subjectivity therein as an "unfolding construal of identity" (p. 3). In this way, subjectivity, authenticity and aesthetic choices are co-dependent. When brands pursue UGC, they engage the desires of convergence culture to have one's subjectivity indulged and included in brand performance, and one's individuated experience shared (Deuze, 2005; Keep, 2014). For this reason, the subjective (in the case of peer to peer marketing) message is more personally resonant. In essence, Instagram posts act as visual testimonials for the brand delivered instantaneously from trusted sources via social networks.

Of course there is both an acceptance and celebration of the aesthetic ramification of this subjectivity. Further to the discussion of the patina of authenticity delivered by non-professional image creation, Jonathan Schroeder (2013) explains: "Snapshot aesthetics signal a step away from corporate control and staging, expanding consumers' role to become both subjects and producers of strategic imagery" and Aaron Frey (2012) finds expression of self-hood and subjectivity in social media as a cycle of remaking, in part as a reaction to "packaged narratives and identities of a globalized consumer culture" (p. 8). In addition, we have seen a rising skepticism of the widespread use of photoshop which has come to be considered a misleading market tool (Leggatt, 2016; Olapic, 2016). This has hastened the preference for user generated imagery which can show, for example, an article of clothing on a real person who may more closely resemble the prospective buyer than an undoubtedly photoshopped model. So again we encounter a distrust and disavowal of mediated imagery as symptomatic of a brand's disinterest in a relationship with eager consumer partners.

How might students engage with this proclivity towards subjectivity? As was discussed above, this can nudge an aesthetic approach towards the everyday or the banal, but this could also work in a very different way, influencing the development and expression of the photographer's own brand. In a business or marketing context, it is increasingly important for students to explore expressions of self, personality, opinion, and personal perspective and understand the ways in which those can be executed in social media spaces. An understanding of the place of the "influencer" in the contemporary media landscape is one area of knowledge that would benefit our students and indeed a study and familiarity with social media as a promotional and expressive tool should be a requirement of any contemporary curriculum.

In another way, though the open and participatory nature of subjective engagement with brands in social media spaces might sidestep aesthetic ambitions or barriers to entry, there might also be an opportunity to exploit this preference for subjective experience by exploring deeply particular stylistic choices. Certainly it might allow expression for one's own particular photographic perspective when engaging with brands in social me- 
dia, especially knowing that marketers are paying attention and willing to be influenced aesthetically themselves (Gillett, 2014). Without a doubt, individual consumer testimonials are compelling regardless of their aesthetic make up but there are clues that subjective experience can be considered, mediated, and even stylized. This is another rich area for study and application by our students in the context of understanding the opportunities inherent in new platforms.

\section{Conclusion}

This paper has attempted to chronicle the massive shifts in contemporary commercial image use and has named three main areas of emerging interest: narrative ability, authenticity, and subjectivity. With these three qualities in mind, this paper seeks to begin a discussion on how post secondary commercial photographic education might meet these needs and rewrite inappropriate and outdated "professional" ambitions for our students. My research suggests that we should focus on the experiential, affective and emotional power of not only a subjective and authentic photographic approach but also within the narrative strength of the image. I have made several suggestions as to how commercial programs might reorganize our priorities to meet the emerging challenges and opportunities posed by the technological and cultural shifts of convergent culture. There are clearly some ambiguities contained herein regarding the juxtaposition of technical skill in storytelling and the authenticity inherent to a seemingly snapshot approach. These ambiguities might pose the most vexing challenge, the answer to which can only be a deep commitment to understanding these new spaces of commercial engagement and experimenting with the tools these spaces provide.

In terms of the limits of this paper, this seeks to be an illumination of important trends and an introduction to the path forward. More research is required to find models of pedagogical approaches that are already addressing these shifts; there are undoubtedly educators who are engaged in a responsive practice with their students. Furthermore, though beyond the scope of this paper, there are opportunities for platform development work-helping brands capture user contributions and creating networks for citizen collaboration in brand initiatives (both commercial and within a mandate of social responsibility). Broadening the scope of what we teach our students to reach into the realms of programming, app development, and technical partnerships will undoubtedly be fruitful.

Without question, there are many interesting avenues of exploration for those committed to a sustained photographic practice. Though the consumer-generated content of which the Domino's campaign was typical seven years ago is still prevalent, there are signs that social media is also creating more space for deliberate image creation and use. Speaking about Instagram's lat- est Snapchat-like feature "Stories", Hugh Pile, L'Oréal's Chief Marketing Officer for Western Europe, explains that the appeal of this new approach comes from a duality: "Within the same platform now we've got this lovely juxtaposition that allows you to tell a richer story, but maybe [providing] a more authentic, or more earthy experience alongside the more polished core visuals" (Handley, 2016). It is crucial then to unlock the possibilities in our students to find these opportunities on platforms that will continue to engage the consumer as brand co-creators.

\section{Acknowledgements}

Thanks to Catherine Jones for early research help and to my co-faculty members for their commitment to providing robust educational opportunities for our students. Also many thanks to my Associate Dean, Donna Braggins and Sheridan College for their support of this paper.

\section{Conflict of Interests}

The author declares no conflict of interests.

\section{References}

American Society of Media Photographers. (2016). Membership categories. ASMP. Retrieved from http:// www.asmp.org/join/membership-categories

Ahearn, M. (2013, June). 21 reasons to love photography now. Photo District News, 46. Retrieved from http://www.pdnonline.com/features/reasons-to-love -photography-now-part-1

Banet-Weiser, S. (2011). Convergence on the street: Rethinking the authentic/commercial binary. Cultural Studies, 25(4/5), 641-658.

Banks, J., \& Deuze, M. (2009). Co-creative labour. International Journal of Cultural Studies, 12(5), 419-431.

Benkler, Y. (2006). The wealth of networks: How social production transforms markets and freedom. New Haven, CT: Yale University Press.

Berger, L. (2011). Snapshots, or: Visual culture's clichés. Photographies, 4(2), 175-190.

Brabham, D. C. (2008). Crowdsourcing as a model for problem solving: An introduction and cases. Convergence: The International Journal of Research into New Media Technologies, 14(1), 75-90.

Bruns, A. (2008). Blogs, Wikipedia, Second Life, and beyond: From production to produsage (Vol. 45). Bern: Peter Lang.

Canadian Association of Professional Image Creators. (2016). Membership categories. CAPIC. Retrieved from http://capic.org/membership-categories/

Chang, C. Y. (2014). Visualizing brand personality and personal branding: Case analysis on Starbucks and Nike's brand value co-creation on Instagram. (Master Thesis). University of lowa, lowa, USA.

Derousseau, R. (2016). 4 Reasons Domino's Pizza (DPZ) 
keeps delivering growth. U.S. News. Retrieved http:// money.usnews.com/investing/articles/2016-03-08/4 -reasons-dominos-pizza-dpz-keeps-delivering-growth

Deuze, M. (2005). Towards professional participatory storytelling in journalism and advertising. First Monday, 10(7). Retrieved from http://firstmonday.org/ojs/ index.php/fm/article/view/1257/1177Beyond

Dewey, C. (2015). Behind the scenes of the world's first true Instagram novel. Washington Post. Retrieved https://www.washingtonpost.com/news/the-interse ct/wp/2015/10/12/behind-the-scenes-of-the-worlds -first-true-instagram-novel

Duffy, B. E. (2010). Empowerment through endorsement? Polysemic meaning in Dove's user-generated advertising. Communication, Culture \& Critique, 3(1), 26-43.

Frey, A. (2012). Pics or it didn't happen: Instagram in prosumer capitalism and reflexive modernity. (Master Thesis). Lund University, Lund, Sweden.

Gillett, R. (2014). How the most successful brands dominate Instagram, and you can too. Fast Company. Retrieved from https://www.fastcompany.com/302 9395/bottom-line/how-the-most-successful-brandsdominate-instagram-and-you-can-too

Gómez Cruz, E., \& Meyer, E. T. (2012). Creation and control in the photographic process: iPhones and the emerging fifth moment of photography. Photographies, 5(2), 203-221.

Gotter, A. (2016). 38 mind-blowing stats about user generated content. Tint. Retrieved from http:// www.tintup.com/blog/38-mind-blowing-stats-effect iveness-user-generated-content

Handley, L. (2016). What does Instagram stories mean for brand engagement? The Guardian. Retrieved from https://www.theguardian.com/media-network/2016 /sep/22/instagram-stories-brand-engagement-loreal -ted-baker

Harper, S. P. (2016). The commercial elephant in the room: The curious silence in the discussions on digital. Take on Art, 2(1), 1-8.

He, W., Zha, S., \& Li, L. (2013). Social media competitive analysis and text mining: A case study in the pizza industry. International Journal of Information Management, 33(3), 464-472.

Hjorth, L. (2008). Being real in the mobile reel: A case study on convergent mobile media as domesticated new media in Seoul, South Korea. Convergence: The International Journal of Research into New Media Technologies, 14(1), 91-104.

Jenkins, H. (2004). The cultural logic of media convergence. International Journal of Cultural Studies, 7(1), 33-43.

Jenkins, H., \& Deuze, M. (2008). Convergence culture. Convergence-London, 14(1), 5-12.

Karpf, D. (2009). Blogs, Wikipedia, Second Life, and Beyond: From production to produsage, by Axel Bruns. Journal of Information Technology \& Politics, 6(1), 81-83.
Keep, D. (2014). The liquid aesthetic of the cameraphone: Re-imagining photography in the mobile age. Journal of Creative Tecnhologies, 4, 128-146.

Kolm, J. (2015). Shine influencers launch in Toronto. Strategy. Retrieved from http://strategyonline.ca/ 2015/11/12/shine-influencers-launches-in-toronto

Laurent, O. (2016). Exclusive: New Getty image subsidiary to focus on commercial work. Time. Retrieved from: http://time.com/4473759/getty-images-subsi diary-news

Lawrence, B., Fournier, S., \& Brunel, F. (2013). When companies don't make the ad: A multimethod inquiry into the differential effectiveness of consumergenerated advertising. Journal of Advertising, 42(4), 292-307.

Leggatt, H. (2016). Consumers more likely to click on ads featuring user-generated photography. BizReport. Retrieved from http://www.bizreport.com/2016/12/ consumers-more-likely-to-click-on-ads-featuring-user -generate.html

Lincoln, A. (2013, March 29) "Domino's 'Show Us Your Pizza' integrated". Retrieved from https:// vimeo.com/52483368

Litz, J. (2010) “Domino's launches 'Show us Your Pizza' campaign." Pizza Market Place. Retrieved from https://www.pizzamarketplace.com/news/dominoslaunches-show-us-your-pizza-campaign

Lyngsfeldt, T. (2015). User generated content beats traditional advertising. AdNews. Retrieved from http://www.adnews.com.au/opinion/user-generated -content-beats-traditional-advertising

Marcus Reker, K. B. (2016). "Why can't run 'like a girl" also mean win the race?": Commodity feminism and participatory branding as forms of self-therapy in the neoliberal advertising space. (Senior Thesis). Scripps College, Claremont, USA.

Marketwired. (2016). Fairmont Hotels \& Resorts partners with NAMARA represents on first-of-its kind photojournalism project. Marketwired. Retrieved from http://www.marketwired.com/press-release/fairmo nt-hotels-resorts-partners-with-namara-representson-first-its-kind-photojournalism-2121777.htm

Meyer, E. T. (2015). The expert and the machine: Competition or convergence? Convergence: The International Journal of Research into New Media Technologies, 21(3), 306-313.

Moore, L. (2015). The ultimate list of marketing statistics for 2015. Freely. Retrieved from https://freely.net/ marketing-statistics

Nava, M., Blake, A., MacRury, I., \& Richards, B. (2013). Buy this book: Studies in advertising and consumption. London: Routledge.

Olapic. (2016). Consumer trust: Keeping it real. Olapic. Retrieved from http://www.olapic.com/consumertrust

Professional Photographers of Canada. (2016). Member benefits. PPoC. Retrieved from https://www. ppoc.ca/en/membership 
San Cornelio, G., \& Gomez Cruz, E. (2014). Co-creation and participation as a means of innovation in new media: An analysis of creativity in the photographic field. International Journal of Communication, 8, 1-20.

Schroeder, J. E. (2008). Visual analysis of images in brand culture. In B. J. Phillips \& E. McQuarrie (Eds.), Go figure: New directions in advertising rhetoric (pp. 277296). Reference Press.

Schroeder, J. E. (2013). Snapshot aesthetics and the strategic imagination. Invisible Culture, 18. Retrieved from https://papers.ssrn.com/sol3/papers.cfm?ab stract_id $=2377848$

Scoblete, G. (2105). How photographers with huge followings grew their social networks. PDNPulse. Retrieved from http://pdnpulse.pdnonline.com/2015 /10/how-to-grow-your-social-network-photography. html
Sooke, A. (2016). Is this the first Instagram masterpiece? Telegraph. Retrieved from: http://www.telegraph.co. uk/photography/what-to-see/is-this-the-first-instagr am-masterpiece

Toffler, A. (1980). The third wave-The classic study of tomorrow. New York, NY: Bantam Books.

Tow Centre. (2015). Image truth/story truth (5/5): What is a photography? The future of photography and the professional image-maker. Retrieved from https:// vimeo.com/146125101

Uzunoğlu, E. (2011). Consumer as advertiser: A conceptual perspective. Global Media Journal: Turkish Edition, 2(3), 138-159.

Wagner, K. (2011). Moblogging, remediation and the new vernacular. Photographies, 4(2), 209-228.

Zappavigna, M. (2016). Social media photography: Construing subjectivity in Instagram images. Visual Communication, 15(3) 271-292.

\section{About the Author}

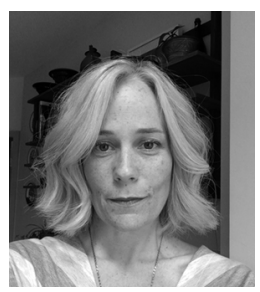

Heather Morton received a Masters Degree in Communication and New Media from McMaster University in Hamilton, Canada. She is currently a Professor in the Honours Bachelor of Photography Program at Sheridan College in Oakville, Canada. She has developed and now teaches courses in Photographic Theory, and the History of Advertising Photography at the senior level. 